the sun was free from spots. I find that I observed the sun, for the purpose of mapping its spots, Dec. 5, at eight A M., Washington (Penn.) local time, and it seemed to be entirely clear. The instrument used was a four-inch refractor. Thinking I might have overlooked some small ones, I observed it again with an eight-inch refractor at half-past one, power of a hundred and fifty, and did not see any spots. The contrast between the sun's face, Dec. 5, 188:, and Nov. 5, 1883 , is very marked. I find I mapped seven groups on Nov. 5, 1883, one of them having eight well-developed spots.

D. J. MCAIAM.

Washington, Penn., Dee. 19.

\section{On the care of entomological museums.}

The editorial comments on this subject in Science for Dec. 19 are certainly very pertinent. For a long time I have been at work on the micro-lepidoptera of North America, until now I have by far the largest collection of the Pyralidae, Tineidae, and Pterophoridae of this country, and a collection of the Tortricidae of the world, fuller and more complete, probably, than any other in existence. My work has hitherto been, in a great measure, to get the insects authentically named by a careful comparison with the original types, in order that the collection, already so large, should prove in some sense an authoritative standard for comparison. 'This work has, of course, given me an opportunity of observing the condition of the types of North-American microlepidoptera in the collections both of this country and Europe, and the care which they have received.

In some American museums the insects are looked after by men who have to gain their livelihood in some vocation remote from the museum. The authorities of other museums have the impression that they have made adequate provisions for the preservation of their insect-collection when it is put under the oversight of an assistant, although he may have no knowledge whatever of such objects. It is not surprising that so many types are represented in these museums by a labelled pin only.

One great trouble is, that many museum officials have very little appreciation of the vast amount of labor, care, skill, and knowledge required to bring together, properly arrange, preserve, and make accessible to those who are competent, and desire to study any one or more of the insects in it, a large and varied collection. One director told me that it did not seem profitable to pay a man two thousand dollars to watch a thousand dollars' worth of insects; and yet he was not at liberty to dispose of them, so they must go to destruction.

At present I believe the museum at Cambridge is the only one in this country which gives assurance that a competent curator of entomology will always be employed; yet I think it is not provided with means to purchase collections of insects. The National museum has appointed an honorary curator; but it might as well be without any as to have one whose entire time is occupied elsewhere, for who would think of donating valuable and perishable types to a museum thus officered!

As matter's now stand, it is better for those who are able to dispose of their collections without a consideration to allow them to go to the Museum of comparative zoölogy; but, if they are not able to give them, they should go into the hands of private individuals who are working on that particular class of insects. It is better for them to be sold to the European museums, where they will be preserved, than for them to go to destruction in a museum of this country. C. H. FERNALD.

State college, Orono, Me.

Your remarks, p. 540, in regard to the preservation of insect-collections are eminently proper and to the point, with the exception of the closing assertion, which is not justified. It is true that the curatorship of insects in the National museum is at present honoraly, and that there is no paid assistant; but it is equally true, that, since my charge of that department, all collections and every single specimen received at the museum have been properly cared for; so that where, up to three years ago, nothing of the many valuable collections brought to the museum remained, there is now the nucleus of a collection; and so long as I am curator of the department, honorary merely though the position may be, no material shall go uncared for. Feeling that a beginning toward a national collection had to be made, and that the museum was the proper place for it, I have thus far given my time to this object in the belief that proper financial provision will be forthcoming for such conduct of the department as will guarantee both the preservation and the future care of collections. When such provision is made, my own private collection, and others that I know of, will be donated to the institution. Until then much valuable entomological material will naturally be lost to the capital.

C. V. Rruey.

[We neither expressed nor intended any slur whatever upon the present honorary curator of the insectcollections of the National museum. As any one can see, our remarks applied to the perpetual care of valuable collections. If they are not insured perpetual care, the less of them that go there the better. And so we repeat, that "the appointment of an honorary curator is worse than useless. It only deceives those who know no better, into the supposition that collections sent to the museum are insured proper care. They are not." We regret if the present honorary curator feels hurt by this ' closing assertion;' but it is the only logical outcome from our previous remarks, which he characterizes 'eminently proper' and to the point.' - E.

\section{THE CHEMICAL LABORATORY OF THE JOHNS HOPKINS UNIVERSITY.}

Is 1876 , the year in which the Johns Hopkins university was opened to students, a small chemical laboratory was built. It was large enough to accommodate about forty working students, and was well equipped with the necessary conveniences for chemical work, from the most elementary to the most advanced. In the course of a few years, temporary desks were put up wherever an available corner could be found, and finally it became evident that a larger building must be erected. Accordingly, the trustees voted to enlarge the old laboratory so as to make room for a hundred students. The work has recently been completed; and, 